\title{
Postpartum depression and physical activity amongst women attending immunization and postnatal clinic in a tertiary hospital in Ibadan
}

Netochi Nwosu ( $\square$ netochinwosu@gmail.com )

University of Ibadan https://orcid.org/0000-0001-8360-1319

\section{Research Article}

Keywords: Postpartum depression, Physical activity, Edinburgh postpartum depression scale, Nigeria

Posted Date: May 24th, 2021

DOI: https://doi.org/10.21203/rs.3.rs-549695/v1

License: (c) (i) This work is licensed under a Creative Commons Attribution 4.0 International License.

Read Full License

Version of Record: A version of this preprint was published at Journal of Research and Health on October 1st, 2021. See the published version at https://doi.org/10.32598/JRH.11.5.1915.1. 


\section{Abstract \\ Background}

Depressive disorders are listed as one important public health issue among women of reproductive age. Postpartum depression is a mental health disorder occurring after childbirth and has disabling effect on mother and child. Amongst other alternative treatment methods, physical activity has been proposed as beneficial especially for mild postpartum depression. Therefore, this study sought to determine the prevalence of postpartum depression, and the association between postpartum depression and physical activity among women in a tertiary hospital in Ibadan.

\section{Methods}

The cross-sectional study was conducted among 401 women attending immunisation and postnatal clinics at the University College Hospital Ibadan. The data was collected using a self-administered questionnaire containing; a self-developed socio-demographic section, Edinburgh postnatal depression scale to measure postpartum depression and International physical activity questionnaire (short type) to assess physical activity. Analysis was done using chi square and a multivariate analysis to determine independent factors. Significance was set at 0.05 .

\section{Results}

More than a third of the respondents (37.8\%) had postpartum depression. Physical activity level was high (72.1\%). High levels of physical activity had 1.25 the odds of postpartum depression as compared to lower levels $(95 \% \mathrm{Cl}=0.797-0.97)$. Gender of child, relationship satisfaction, age of child, were independently associated with postpartum depression.

\section{Conclusion}

This study shows that prevalence of postpartum depression is greater than previously reported in past studies in southwest Nigeria and high levels of physical activity may increase the risk of postpartum depression.

\section{Introduction}

Among all common mental health disorders depression is the most common illness affecting people and by the year 2020 is expected to be second most prevalent health problem in general ${ }^{1}$. In 2004, the World Health Organisation estimated that $10 \%$ of the over 150 million people living with depressive disorders were in Africa. Among women of reproductive age depressive disorders lead universally ${ }^{2}$. Due to the greater prevalence of depression among females as compared to males, maternal mental health has 
become a vital public health issue and poses a challenge across the globe. The most common mental health challenge post childbirth is postpartum depression, an overwhelming illness that impairs maternal behavior $^{3}$. Postpartum depression (PPD) is classified as a major depressive episode that begins within 4 or 6 weeks of childbirth by the Diagnostic and Statistical Manual of Mental Disorders and 10th edition of the International Classification of Diseases respectively ${ }^{4}$. Although onset must be within $4-6$ weeks, it is believed that women remain exposed to the risk of PPD even up to 14 months after delivery ${ }^{5,6}$.

Reported as affecting around 1 in 10 women at some time in the first year ${ }^{7}$, studies have shown a diverse range of prevalence. Halbreich \& Karkun (2006) in a review of literature reports a prevalence of about $0 \%$ to almost $60 \%$ from one continent to another ${ }^{8}$. A literature review on lower-middle-income countries have placed the prevalence of PPD at approximately $20 \%{ }^{9}$. According to studies conducted in Nigeria, about $10-30 \%$ of women attending primary care have PPD ${ }^{10}$ while Abiodun (2006) in similar population reported a prevalence of $18.6 \%$ in developing society ${ }^{11}$.

Several factors; psychological, biological, and social have been fingered in the etiology of PPD and have shown positive association. Psychosocial risk factors such as history of depression, poor relationship with spouse, weak social support, stressful periods/events prior to birth, poor social status, stress of childcare and complications during birth have been strongly associated with postpartum depression $3,4,12$. General treatment of PPD includes medication and psychotherapy. Side effects of these drugs however are relatively unknown especially as it relates to its effects in breast milk ${ }^{13,14}$ coupled with reports on relapses and other adverse effects ${ }^{15}$ hence non-pharmacologic approaches have come highly recommended. Conversely, studies have shown that participation in some form of physical activities (leisure time activity or moderate to vigorous activity) improves PPD symptom ${ }^{16-19}$. Seeing as postpartum depression has proven negative effect on both the woman, infant and family, any effective treatment should therefore explore all available options of treatment including physical activity. To the best of my knowledge, no study has explored the relationship between physical activity and postpartum depression in Nigeria hence prompting this study whose main aim was to determine the prevalence of postpartum depression and the relationship between physical activity and postpartum depression. Other objectives included determining other risk factors in postpartum depression.

\section{Methods}

\section{Participants}

The cross-section study was carried out at the University College Hospital which is a multidisciplinary tertiary hospital in Ibadan attending to a mix of patients from all over. The target population for the study were infant nursing mothers that came for immunization at the child welfare clinic of the Institute of child health and postnatal clinic at the University College Hospital, Ibadan. Mothers who had a delivery within the 12 months preceding this study, who were at least four weeks post-delivery were included. Women who were pregnant were excluded. 


\section{Study design}

Total sampling method was employed for this study. This was due to the number of women attending the child welfare and postnatal clinics which was about 300 women per month and the study duration which was scheduled for six weeks. All consenting respondent available during the six weeks' duration of this study were surveyed until the required study size was achieved. The study size was determined using the Leslie Kish formula,

$$
\mathrm{n}=\frac{\mathrm{Z} \alpha^{2} \mathrm{p} \mathrm{q}}{\mathrm{d}^{2}}
$$

Where $\mathrm{P}=30.6 \% ; \mathrm{q}=69.4 \% ; \mathrm{Za}=\mathbf{=}$ standard normal deviate corresponding to $95 \%$ confidence interval, critical value of $1.96 ; d=0.05$

Using a previously reported prevalence of $30.6 \%$ in a Nigerian study ${ }^{20}$, the sample size was calculated to be 326 . Using a $10 \%$ anticipated non-response rate, sample size was rounded up to 400 . In totality 401 women participated in the study

\section{Data collection}

The questionnaire which was filled by the respondents was in English language and consisted of three sections.

- A-Socio-demographic section containing personal information (age, religion, tribe, educational status, marital status, family type, employment status, occupation), family and social history (number of children, ever lost a child, help with child, relationship satisfaction, agreement with partner on finance, decision making and finance), Child and obstetric history (age of present child, illness during pregnancy, mode of delivery, desired gender, complications during pregnancy, history of depression)

- B- The Edinburgh Postnatal Depression Scale (EPDS): The scale, which consists of 10 questions, asks the respondent how they have been feeling over the last one week. Responses are ranked from 0 to 3 , according to severity, with an overall score of 30. This study used a score of 10 as it's cut off for PPD. This score has been suggested for the detection of mild depression ${ }^{21}$. As reported by Adewuya et al, (2005), "At cut-off score of 10 the EPDS was found to be the best for screening for both major and minor depression (sensitivity $=0.867$, specificity $=0.915$, Diagnostic Likelihood Ratio for a positive result $=10.200)^{\prime 21}$.

- C- International Physical Activity questionnaire-SF (IPAQ): consisting of seven questions that measures individuals' past 7-day levels of physical activity, this scale measure the various intensities of physical activity that people do as part of their daily activities and time spent sitting and estimates total physical activity in metabolic equivalent of task (MET) per min/week and estimated sitting time. 
The types of activity assessed were walking, moderately intense activities and vigorous activities. Categorical scoring method classifies physical activity into low, moderate or high according to the number of hours and days spent in moderate or vigorous physical activities and walking. The examples of physical activities given in the IPAQ was fine-tuned to reflect activities that are common to this environment and was validated by a content expert (physiotherapy department). The activities were chosen from the compendium of physical activities and had the same Metabolic Equivalent of Task as the original activities given. Categorical scoring was graded as,

Low-No activity OR Some activity is reported but not enough to meet Categories 2 or 3.

Moderate- any of the following 3 criteria: 3 or more days of vigorous activity of at least 20 minutes per day OR 5 or more days of moderate-intensity activity and/or walking of at least 30 minutes per day OR 5 or more days of any combination of walking, moderate-intensity or vigorous intensity activities achieving a minimum of at least $600 \mathrm{MET}$-minutes/week.

High: any one of the following 2 criteria: Vigorous-intensity activity on at least 3 days and accumulating at least 1500 MET-minutes/week OR 7 or more days of any combination of walking, moderate- or vigorous-intensity activities accumulating at least 3000 MET-minutes/week" (http://www.ipaq.ki.se).

IPAQ has shown to be appropriate for use in developed or developing countries and has good evidence of test-retest reliability ${ }^{22}$.

\section{Data Analysis}

Data were analyzed using SPSS version 20. Data collected at the end of each day was checked for errors and cleaned. Questionnaires with missing data were discarded. A research assistant was present to help with any difficulties the respondents encountered. Data was categorised into women with EPDS scores above 10 as having symptoms of depression and below 10 as not having depressive symptoms. Physical activity was categorised as low, moderate or high. Descriptive statistics such as frequencies and percentages were used to summarize and present qualitative data. Relationship satisfaction was determined from three questions which were picked from the couple satisfaction index; in general, how often do you think things are going on well between you and your partner, do you feel like a team with your partner, does your partner meet your needs. Responses were ranked on a likert scale of 0-5 and summed up to 15. Relationship satisfaction was categorised as; poor (0-5), moderate (6-10) and good (11-15). Chi square test was used to determine the association between postpartum depression (dependent variable) and physical activity (independent variable). Bivariate analysis was also performed to explore the independent variables that were significantly associated with PPD at a significance level of $10 \%$. Logistic regression was performed for all significant variables from the bivariate analysis to determine the odd ratio and $95 \% \mathrm{Cl}$ at a significance level of $5 \%$.

\section{Results}


From a total of 600 women proposed to participate, 401 women willingly participated. Almost half of the women (43.1\%) were within the age range of $30-34$ while about $27 \%$ were above $35 y e a r s$. The mean age of respondents was $31.8 \pm 4.1$, with the age range of $20-50$ years. Most were Yoruba (88\%), the dominant ethnic tribe of south west, Christian (84\%) and tertiary education (79.6\%). Three quarter of the respondents had less than two children (76.5\%) while $32.9 \%$ were between three months to six months. Half had some sort of support for childcare and almost all had their desired gender at birth (86.3\%) and were in monogamous marriages (83.3\%). Most of the respondents agreed with their partners on major decisions (87.3\%), issues concerning finances (88\%) and in-laws (79.8\%). Most also reported having good relationship satisfaction with their partners (85.8\%). Two-third of the respondents were healthy during pregnancy (78.6\%) while almost all had no complications at birth (92.5\%). About 59.7\% of respondents had normal delivery and less than $10 \%$ had medical history of depression (Table 1).

\section{Prevalence of Postpartum depression and physical activity}

Prevalence of PPD was 37.8\%. Mean postpartum depression score was $8.15( \pm 4.7)$ with scores ranging from $0-26$. Suicidal ideation was reported by 31 women $(7.7 \%)$ who answered above 1 in the $10^{\text {th }}$ question of the EPDS scale.

Physical activity (PA) was generally high. Among the women, 41.2\% had moderate levels of physical activity and $30.9 \%$ had higher levels of physical activity. In general, $72.1 \%$ of respondents were physically active while $27.9 \%$ had low physical activity.

\section{Postpartum depression and physical activity}

There was no statistically significant association between PPD and physical activity $(p=0.327)$, but those with higher physical activity had an increased risk of having PPD (OR=1.255, 95\% Cl=0.797-0.977) (Table 2).

\section{Postpartum depression and other variables}

Family type $(p<0.001)$, age of child $(p=0.025)$, number of children living $(p=0.019)$ and desired gender $(p=0.026)$ were statistically associated with postpartum depression. Maternal age $(p=0.912)$, support for childcare $(p=0.220)$, previously lost a child $(p=0.413)$ and marital status $(p=0.156)$ were not statistically associated with postpartum depression (Table 2). Medical history of depression pre-pregnancy was significantly associated with postpartum depression $(p=0.086)$. Agreement with partner on family finances $(p=0.026)$, ways to deal with in-laws $(p=0.008)$, decision making $(p=0.008)$ and relationship satisfaction $(p<0.001)$ were also significantly associated with postpartum depression (Table 3 )

\section{Multiple regression}

Age of child was statistically associated with postpartum depression. Mothers with child between 6 weeks-3months were independently associated with postpartum depression $(\mathrm{OR}=0.24 ; 95 \% \mathrm{Cl}=0.06$ 0.89). Women with children between 6 weeks-3months are at less risk to have PPD than women with 
children above 9 months. Family type had a statistically independent significant association with postpartum depression. Women who were in polygamous marriages were three times more likely to have postpartum depression than those that were in monogamous family $(\mathrm{OR}==3.49 ; 95 \% \mathrm{Cl}=1.83-6.65)$ and single parents were less likely $(\mathrm{OR}=0.66 ; 95 \% \mathrm{Cl}=0.14-3.06)$. Women who reported having the desired gender were also less likely $(\mathrm{OR}=0.47 ; 95 \% \mathrm{Cl}=0.24-0.93)$ to report postpartum depression symptoms than those who did not have their desired gender. Relationship satisfaction was independently associated with postpartum depression $(\mathrm{OR}=2.664 ; 95 \% \mathrm{Cl}=1.317-5.390)$. Those with poor/ moderate relationship satisfaction were twice as likely to have postpartum depression than those in a good relationship with partner (Table 4).

\section{Discussion}

This study showed a high prevalence of $37.8 \%$ which is comparable to some other Nigerian studies done in similar hospital setting ${ }^{20,23}$. In Nigeria varying rates from $10-44 \%$ has been reported from different regions of the country $21,24-26$. This wide range prevalence is also reflected in Africa as well as other continents ${ }^{27}$. However, majority of developing countries have estimated prevalence rates higher than that those found in high-income countries $27,28,29$. This variability from country to country could be due to study design (diagnostic tool, cut off scores, period of assessment), cross cultural differences, socioeconomic terrain, and perception of PPD/ mental health. This further indicates that a woman's susceptibility to postpartum depression is not based on geographical location but on social, economic, psychological and biological factors that thrive in enabling environments.

With three quarter of the women reporting moderate to high physical activity (PA), prevalence of physical activity was quite high $(72.1 \%)$. Although there was no exact study measuring PA in postpartum women in Nigeria, however two Nigerian studies report $79 \%$ and $52.2 \%$ postnatal exercises engagement ${ }^{30,31}$ with activity participation differing from this study. Other foreign studies have shown lower physical activity levels ${ }^{16,32}$. Though High PA in this study could be due to the economic terrain which necessitates a woman getting back to work shortly after whilst joggling home care, the high levels of PA could be because a one-year range was used. Physical activity was found to be lesser in the immediate postpartum period and increased constantly throughout the postpartum period. This may also have influenced the high rate reported. The increasing levels of PA down the postpartum period may reflect the reduction in help and support earlier received and more women being comfortable participating in PA. This was similarly reported by Borodulin et al. (2009) ${ }^{33}$. Women think it unsafe to participate in physical activity earlier than three months postpartum ${ }^{31}$.

There was no statistically significant association between postpartum depression and physical activity (PA) levels in this study. This was similarly reported by Daley et al. (2008) and Saligheh, et al. (2014) 7,34. The latter was a cross sectional study assessing physical activity and postpartum depression amongst women from post puerperal to the first-year post delivery, similar with this present study. Other studies however report exercise to be effective in preventing and treating mild to moderate depression ${ }^{18.19,35-38}$. 
These studies were either experimental or a review of literature. Although there was no significant association, high PA increased the chances of developing PPD symptoms as compared to lower PA. This finding is buttressed by Demissie et al. (2011) who reported women who had high levels of PA had twice the risk of developing elevated depressive symptoms ${ }^{17}$. High PA in this study involved vigorous exercises which were household activities and walking than activities performed for leisure. It has been reported that leisure/outdoor physical activity reduces PPD as compared to activities due to childcare or household work ${ }^{17,39}$

Age of child which is illustrative of the postpartum period was significantly associated with postpartum depression. Mothers with younger babies were less likely to have postpartum depression compared with older babies. This finding is similar with those of Saligheh et al. (2014) and Shorey et al. (2018) 34,40. Shorey et al. (2018) who reviewed the literature using healthy women noted a general increasing prevalence with age of child. Age of child, which is a proxy for postpartum period, was associated with an increase in prevalence of postpartum depression as the period progresses. Bugdayci, et al. (2004) reports PPD prevalence increased from 29\% (0-2-month) to 36\% (7-12months) and higher above 13 months ${ }^{41}$. This increase in PPD may account for higher outcomes of PPD in later postpartum periods than earlier ones $^{2,42}$. With the significant waning of physical, financial and emotional support from friends and family coupled with the mother's full participation in home activities, childcare, employment and/or business, one might see how this could account for increased PPD.

Most studies have found positive association between relationship satisfaction and PPD, this study wasn't any different. Whilst marital satisfaction has been suggested as a mild predictor of PPD, its effect is majorly based on the perceived level of support; physical, financial and emotional the woman receives in the relationship $3,43,44$. This same perceived satisfaction can be connected to the effect family setting has on PPD. In this study family setting was independently associated with postpartum depression with polygamy conferring a three-fold increase in postpartum depression than women in monogamous marriage. This finding is similarly reported in other studies done in traditional societies ${ }^{44,45}$. In contrast, Ghosh \& Goswami (2011) and Rahman et al. (2003) found women coming from nuclear family suffer more from PPD ${ }^{46,47}$. The quality of the relationship with the husband and type of support received could determine the impact of family setting on postpartum symptoms.

Gender of the child showed a positive risk factor for postpartum depression. This is similar to other studies done both in Nigeria ${ }^{11}$ and other traditional societies ${ }^{43,48}$ where the husband's or even the wife's disappointment with the gender of the baby is significantly associated with developing postpartum depression, specifically if the baby is a girl. This is especially seen if the woman already had a female child. This preference most Africans have for male children as heirs and progenitor of family puts pressure on the woman. Comparably, in some western studies similar relationship did not exist between the gender of the child and postpartum depression ${ }^{29,49}$.

\section{Conclusion}


Postpartum depression is prevalent here in Nigeria and is generally higher than the speculated $10-15 \%$. It is a global health issue that should be taken seriously as it cuts across both low- and high-income countries and associated factors are dependent upon cultural and socio-economic terrain. It is no longer a myth that can be swept under the carpet but should be openly addressed and necessary systems put in place, especially in tertiary hospitals that attends to a mix of mothers in the society, in other to enable healthier, happier families. This study hopes to encourage further research in this direction.

\section{Limitations}

A standard scale was not used to assess relationship satisfaction therefore the result should be interpreted with caution. Also, as a cross sectional study I could not determine temporal association between postpartum depression and physical activity. In as much as the study population was a mix of people, the sample population may not reflect this diversity as most were educated, consequently a generalization must be carefully made.

\section{Abbreviations}

PPD: Postpartum depression

PA: Physical activity

IPAQ-SF: International physical activity questionnaire- short form

EPDS- Edinburgh postpartum depression scale

MET: Metabolic equivalent of time

SPSS: Statistical Package for Social Science

Cl: Confidence interval

\section{Declarations}

Acknowledgement: I would like to acknowledge the support received from my Supervisor, Dr. Pelumi Adebiyi and the management, staff and women who attended the Immunisation and postnatal clinics of University college hospital, Ibadan, and were generous with their time.

\section{DECLARATION}

Ethics and consent to participate: Approval for the study was sought from the University of Ibadan / University College Hospital Health Research Ethics Committee (UI/UCH/EC/16/0103). Permission was also sought from the authorities of the immunisation clinic (Institute of child health, UCH) and postnatal clinic (Obstetrics and gynaecology department, $\mathrm{UCH}$ ) where the study was carried out. Written informed consent was obtained from respondents after informing them of the purpose, intent, voluntary and non- 
maleficence of the study. Confidentiality was maintained in the questionnaire by keeping them anonymous.

Consent for publication: Not applicable

Availability of data and material: The datasets used and/or analysed during the current study are available on reasonable request.

Competing interests: I declare no competing interest.

Funding: Not applicable

Authors' contributions: Not applicable

\section{Tables}

Table 1: Descriptive data for Socio-demographic factors 


\begin{tabular}{llc}
\hline Variables & $\begin{array}{l}\text { Frequency } \\
(\mathbf{N = 4 0 1 )}\end{array}$ & $\begin{array}{c}\text { Percentage } \\
\text { (\%) }\end{array}$ \\
\hline Mother's age & 11 & 2.7 \\
$\square 25$ & 106 & 26.4 \\
$25-29$ & 173 & 43.1 \\
$30-34$ & 111 & 27.7 \\
$\geq 35$ & & 84 \\
Religion & & 15.7 \\
Christian & 337 & 0.3
\end{tabular}

\section{Ethnic group}

Yoruba

Igbo

354

88.3

Others*

20

4.8

27

6.9

\section{Educational status}

Primary

Secondary

Tertiary

Others

Marital status

Single

Married

Family type

Monogamous

Polygamous

Single parenting

Employment status

Employed

Unemployed

1

29

319

52

6

395

334

54

13

355

46

Number of children living

Less than two children

More than two children

Age of present child

Less than 6weeks

7weeks-3months

$>3$ months-6months

$>6$ months-9months

$\square 9$ months-12months

Previously lost a child

Yes

No

307

94

94

99

132

61

15

28

373

203

198

348

86.8 
Agreement with partner in making major decisions

Yes

No

Agreement with partner concerning family finances

Yes

No

Agreement with partner in ways of dealing with in-laws

Yes

No

Level of relationship satisfaction

Poor

Moderate

Good

$\begin{array}{ll}6 & 1.5 \\ 49 & 12.2 \\ 346 & 86.3\end{array}$

Illness during pregnancy

Yes

85

316

21.2

No

Complications at birth

Yes

30

371

Mode of delivery

Vagina

$\mathrm{C} / \mathrm{S}$

Forceps

Medical history of depression pre-pregnancy

Yes

No

\section{5}

164

2

30

371
78.8

7.5

92.5

57.9

40.6

1.5

*Others include Edo, Hausa, Delta

$<$ (less than), > (greater than), $\geq$ (greater than or equal to)

Table 2. Association between postpartum depression and physical activity

\begin{tabular}{lccccc} 
Variable & \multicolumn{2}{c}{ PPD } & Unadj OR & $95 \%$ CI & value $^{\text {p- }}$ \\
Physical activity & Yes & No & & & value
\end{tabular}

Physical activity

$$
116(40.1) \quad 173(59.9)
$$

Low physical activity

$39(34.8)$

$73(65.2)$

1.255

$0.797-0.97$ 


\begin{tabular}{|c|c|c|c|}
\hline Variables & \multicolumn{2}{|c|}{ PPD $(\geq 10)$} & value $^{\mathrm{p}-}$ \\
\hline Maternal age & & & \multirow{6}{*}{0.912} \\
\hline 025 & $4(34.6)$ & $7(63.6)$ & \\
\hline $25-29$ & $38(35.8)$ & $68(64.2)$ & \\
\hline $30-34$ & 69 (39.9) & $104(60.1)$ & \\
\hline$\geq 35$ & $44(39.6)$ & $67(60.4)$ & \\
\hline Education & & & \\
\hline Secondary & $14(48.3)$ & $15(51.7)$ & \multirow[t]{3}{*}{0.540} \\
\hline Tertiary & $121(37.9)$ & 198(62.1) & \\
\hline Others & $20(38.5)$ & $32(61.5)$ & \\
\hline Employment & & & \multirow{3}{*}{0.802} \\
\hline Employed & 138(38.9) & $217(61.1)$ & \\
\hline Unemployed & $17(37)$ & $29(63)$ & \\
\hline Family type & & & \multirow{4}{*}{$0.000 *$} \\
\hline Polygamous & $34(63)$ & $20(37)$ & \\
\hline Monogamous & $115(34.4)$ & $219(65.6)$ & \\
\hline Single parenting & $6(46.2)$ & $7(53.8)$ & \\
\hline Religion & & & \multirow{3}{*}{0.105} \\
\hline Christian & $124(36.8)$ & 213(63.2) & \\
\hline Islam & $30(47.6)$ & $33(52.4)$ & \\
\hline Marital status & & & \multirow{3}{*}{0.156} \\
\hline Married & $4(66.7)$ & $2(33.3)$ & \\
\hline Single & $151(38.2)$ & $244(61.8)$ & \\
\hline Had support for child & & & \multirow{3}{*}{0.220} \\
\hline Yes & $72(35.6)$ & $130(64.4)$ & \\
\hline No & $82(41.6)$ & $115(58.4)$ & \\
\hline Number of children living & & & \multirow{3}{*}{$0.019 *$} \\
\hline Less than 2 & 109(35.5) & 198(64.5) & \\
\hline More than 2 & $46(48.9)$ & $48(51.1)$ & \\
\hline Have you previously lost a child & & & \multirow{3}{*}{0.413} \\
\hline Yes & $14(53.8)$ & $12(46.2)$ & \\
\hline No & $231(61.9)$ & $142(38.1)$ & \\
\hline Age of present child & & & \multirow{6}{*}{$0.025 *$} \\
\hline प6weeks & $33(35.1)$ & $61(64.9)$ & \\
\hline 6weeks-3mths & $29(29.3)$ & $70(70.7)$ & \\
\hline$>3$ mths-6mths & $59(44.7)$ & $73(55.3)$ & \\
\hline$>6$ mths-9mths & $24(39.3)$ & $37(60.7)$ & \\
\hline 09 mths- 12 mths & $10(66.7)$ & $5(33.3)$ & \\
\hline Had Desired child gender & & & \multirow{3}{*}{$0.026^{*}$} \\
\hline Yes & $72(20.8)$ & $274(79.2)$ & \\
\hline No & $18(34.6)$ & $34(65.4)$ & \\
\hline Illness during pregnancy & & & \multirow{3}{*}{0.183} \\
\hline Yes & $39(46.4)$ & $45(53.6)$ & \\
\hline No & $121(38.4)$ & $194(61.6)$ & \\
\hline \multicolumn{4}{|l|}{ Mode of delivery } \\
\hline Yes & $91(39.2)$ & $141(60.8)$ & \multirow[t]{3}{*}{0.717} \\
\hline No & $61(37.4)$ & $102(62.6)$ & \\
\hline Complication at birth & & & \\
\hline Yes & $15(50)$ & $15(50)$ & \multirow[t]{2}{*}{0.176} \\
\hline No & $138(37.5)$ & $230(62.5)$ & \\
\hline
\end{tabular}


Medical history of depression pre-pregnancy

Yes

No

15(53.6) 13(46.4)

$0.086 * *$

Agreement with partner concerning family 137(37.2) 231(62.8) finances

Yes

128(36.3) 225(63.7)

$0.026^{*}$

No

Agreement with partner in ways of dealing with in-laws

Yes $24(53.3) \quad 21(46.7)$

No

112(35) 208(65)

$0.008^{*}$

Agreement with partner in decision making $40(51.3) \quad 38(48.7)$

Yes

No

128(36.6) 222(63.4)

$0.008^{*}$

Relationship satisfaction

Poor/ moderate

Good

24(50) 24(50)

33(63.5) $\quad 19(36.5)$

$0.000^{*}$

118(34.2) 226(65.7)

*Significant level 0.10

Table 4. Multivariate analysis 


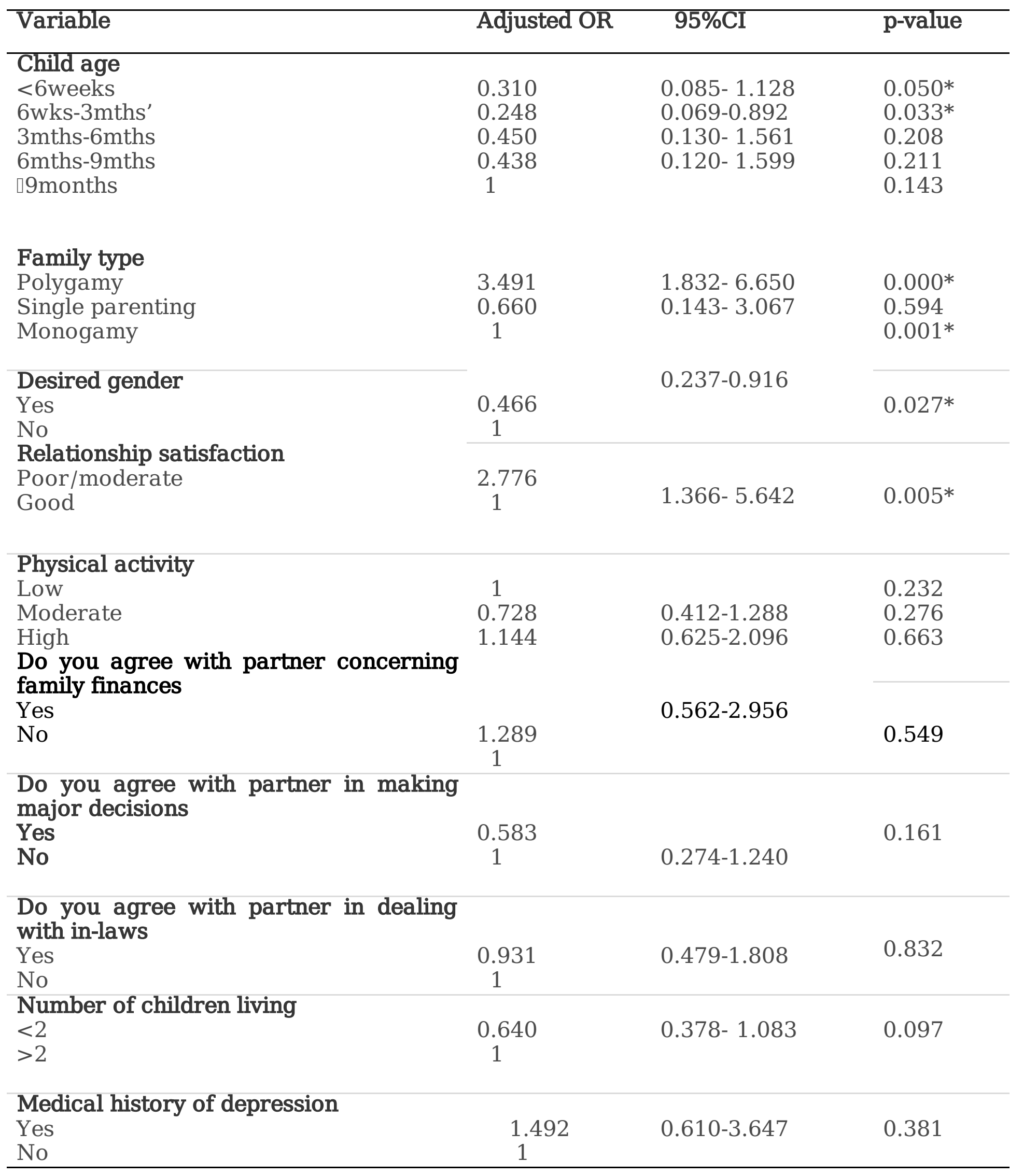

*Significance set at 0.05 


\section{References}

1. Hewitt CE, Gilbody SM, Brealey S, Paulden M, Palmer S, Mann R. Methods to identify postnatal depression in primary care: an integrated evidence synthesis and value of information analysis. Health Technol Assess. 2009;13(36)

2. World Health Organization. The global burden of disease: 2004 update. Geneva. https://www.who.int/healthinfo/global_burden_disease/projections2004. Assessed 2018

3. Norhayati M, Hazlina NN, Asrenee A, Emilin WW. Magnitude and risk factors for postpartum symptoms: a literature review. Journal of affective Disorders.2015;175:34-52.

4. Stewart DE, Robertson E, Dennis CL, Grace SL, Wallington T. Postpartum depression: literature review of risk factors and interventions. University Health Network Women's Health Program.2003: 9.

5. Goodman JH. Postpartum depression beyond the early postpartum period. Journal of obstetric, gynecologic, and neonatal nursing. 2006;33: 410-420.

6. Leitch S. Postpartum Depression: A Review of the Literature. St. Thomas, Ontario: Elgin-St. Thomas Health Unit 2002.

7. Daley AJ, Winter H, Grimmett C, McGuinness M, McManus R \& MacArthur C. Feasibility of an exercise intervention for women with postnatal depression: a pilot randomised controlled trial. British Journal of General Practice 2008; 58:178-183.

8. Halbreich U, Karkun S. Cross-cultural and social diversity of prevalence of postpartum depression and depressive symptoms. J Affect Disord.2006;91:97-111 doi: 10.1016/j.jad.2005.12.051

9. Fisher J, MCd M, Patel V, Rahman A, Tran T, Holton S, Holmes W. Prevalence and determinants of common perinatal mental disorders in women in low and lower-middle-income countries: a systematic review. Bull World Health Organ.2012; 90(2): 139-49H. doi: 10.2471/BLT.11.091850

10. Gureje O, Oladeji BD, Araya R, Montgomery AA, Kola L, Kirmayer L et al. Expanding care for perinatal women with depression (EXPONATE): study protocol for a randomized controlled trial of an intervention package for perinatal depression in primary care. BMC Psychiatry 2015; 15: 136.

11. Abiodun OA. Postnatal depression in primary care populations in Nigeria. Gen Hosp Psychiatry 2006; 28: 133-6 doi: 10.1016/j.genhosppsych.2005.11.002

12. Dennis CL, Chung-Lee L. Postpartum depression help-seeking barriers and maternal treatment preferences: A qualitative systematic review. Birth 2006;33(4):323-31.

13. Eberhard-Gran M, Eskild A, Opjordsmoen S. Use of Psychotropic Medications in Treating Mood Disorders During Lactation: Practical Recommendations. CNS Drugs 2006;20, 187-198

14. Fitelson E, Kim S, Baker AS, \& Leight K. Treatment of postpartum depression: clinical, psychological and pharmacological options. International journal of women's health. 2010;3: 1-14.

15. Wisner KL, Perel JM, Peindl KS, Hanusa BH, Findling RL, Rapport D. Prevention of recurrent postpartum depression: a randomized clinical trial. J. Clin Psychiatry, 2001; 62, 82-86.

16. Bahadoran P, Tirkesh F, Oreizi HR. Association between physical activity 3-12 months after delivery and postpartum well-being. Iranian Journal of Nursing and Midwifery Research, 2014;19(1): 82-87 
17. Demissie Z, Siega-Riz A-M., Evenson KR, Herring AK, Dole N., Gaynes BN. Associations Between Physical Activity and Postpartum Depressive Symptoms. J Womens Health (Larchmt)2011; 20(7): 1025-1034

18. Dunn AL, Trivedi MH, Kampert J, Clark CG, Chambliss HO. The DOSE study: a clinical trial to examine efficacy and dose response of exercise as treatment for depression. Controlled Clinical Trials 2002; 23(5): 584-603.

19. Okyay EK, Ucar T. The effect of physical activity level at postpartum period on quality of life and depression level. Med. Sci. 2018; 7:587-593.

20. Ukaegbe Cl, Iteke OC, Bakare MO, Agbata AT. Postpartum Depression among Igbo Women in an Urban Mission Hospital, South East Nigeria. Ebonyi Medical Journal 2012; 11 (1\&2):29-36.

21. Adewuya AO, Eegunranti AB, Lawal AM. Prevalence of postnatal depression in Western Nigerian women: a controlled study. Int J Psychiatry Clin Pract. 2005;9:60-4 doi: 10.1080/13651500510018211.

22. Oyeyemi, AL, Oyeyemi A, Adegoke B, Oyetoke, FO \& Umar S. Cross cultural adaptation of the International Physical Activity Questionnaire: reliability and validity of the Hausa version in Nigeria. BMC Med Res Methodol. 2011; 11.

23. Agbaje, OS, Anyanwu, JI, Umoke, P, Iwuagwu TE, Iweama CN, Ozoemena, EL et al. Depressive and anxiety symptoms and associated factors among postnatal women in Enugu-North Senatorial District, South-East Nigeria: a cross-sectional study. Archives of public health = Archives belges de sante publique, 77: 1.

24. Obindo TJ, Ekwempu CC, Ocheke AN, Piwuna CG, Adegbe EO, Omigbodun OO. Prevalence and correlates of postpartum depression in a teaching hospital in Nigeria. Highland Med Res J, 2013;1:71-5.

25. Sulyman D, Ayanda KA, Dattijo LM, Aminu BM. Postnatal depression and its associated factors among Northeastern Nigerian women. Ann Trop Med Public Health.2016;9:184-90.

26. Uwakwe R. Affective (depressive) morbidity in puerperal Nigerian women: validation of the Edinburgh postnatal depression scale. Acta Psychiatr Scand 2003;107:251-9 doi: 10.1034/j.16000447.2003.02477.

27. Parsons CE, Young KS, Rochat TJ, Kringelbach ML, Stein A. Postnatal depression and its effects on child development: a review of evidence from low- and middle-income countries. Br. Med. Bull. 2012;101:57-79.

28. Josefsson A. Postpartum Depression- Epidemiological and Biological aspects. Linköping University Medical Dissertation 2003;781

29. Lanes A, Kuk JL, \& Tamim H. Prevalence and characteristics of Postpartum Depression symptomatology among Canadian women: a cross-sectional study. BMC Public Health.2011; 11: 302.

30. Mbada, CE, Adebayo, OE, Awotidebe, TO. Practice and pattern of antenatal and postnatal exercise among Nigerian Women. A cross sectional study. International journal of women's health and 
reproductive sciences 2015: 3(2): 93-98.

31. Juříková J, Havelka R. Physical Activity in Puerperium Period. The European Proceedings of Social \& Behavioural Science. 2019;02: 37

32. Borodulin KM, Evenson KR, Herring AH. Physical activity patterns during pregnancy through postpartum. BMC Womens Health. 2009; 9: 32

33. Adeniyi A, Ogwumike 0 \& Bamikefa, T. Postpartum Exercise among Nigerian Women: Issues Relating to Exercise Performance and Self-Efficacy. ISRN obstetrics and gynecology. 2013; 294518. $10.1155 / 2013 / 294518$.

34. Saligheh M, Rooney RM, McNamara B, \& Kane RT. The relationship between postnatal depression, sociodemographic factors, levels of partner support, and levels of physical activity. Frontiers in psychology, 2014;5: 597.

35. Armstrong $\mathrm{K}$, and Edwards $\mathrm{H}$. The effects of exercise and social support on mothers reporting depressive symptoms: a pilot randomized controlled trial. Int. J. Mental Health Nurs.2003; 12:130138.

36. Da Costa D, Lowensteyn I, Abrahamowicz M, Ionescu-Ittu R, Dritsa M, Rippen N, et al. A randomized clinical trial of exercise to alleviate postpartum depressed mood. Journal of psychosomatic obstetrics and gynaecology 2009;30(3): 191-200.

37. Daley AJ, Blamey RV, Jolly K, Roalfe AK, Turner KM, Coleman S, McGuinness M, et al. A pragmatic randomized controlled trial to evaluate the effectiveness of a facilitated exercise intervention as a treatment for postnatal depression: the PAM-PeRS trial. Psychological medicine 2015; 45(11): 24132425

38. Kołomańska-Bogucka, D, \& Mazur-Bialy Al. Physical Activity and the Occurrence of Postnatal Depression-A Systematic Review. Medicina (Kaunas, Lithuania) 2019; 55(9): 560.

39. Teychenne M, York R. Physical activity, sedentary behavior, and postnatal depressive symptoms: a review. American Journal of Preventive Medicine 2013; 45: 217-227.

40. Shorey S, Chee C, Ng ED, Chan YH, Tam W, \& Chong YS. Prevalence and incidence of postpartum depression among healthy mothers: A systematic review and meta-analysis. Journal of psychiatric research 2018;104: 235-248.

41. Bugdayci CR, Sasmaz T, Tezcan H, Kurt AO, Öner S. A cross-sectional prevalence study of depression at various times after delivery in Mersin province in Turkey. Journal of Women's Health 2004;13: 6368.

42. Chandran M, Tharyan P, Muliyil J, Abraham S. Post-partum depression in a cohort of women from a rural area of Tamil Nadu, India: incidence and risk factors. Br J Psychiatry 2002; 181: 499-504 doi: 10.1192/bjp.181.6.499

43. Patel V, Rodrigues M, DeSouza N. Gender, poverty, and postnatal depression: a study of mothers in Goa, India. Am J Psychiatry 2002; 159: 43-7 doi: 10.1176/appi.ajp.159.1.43

44. Fatoye FO, Oladimeji BY, Adeyemi AB. Difficult delivery and some selected factors as predictors of early postpartum psychological symptoms among Nigerian women. J Psychosom Res.2006;60: 
299-301.

45. Ho-Yen SD, Tschudi Bondevik GT, Eberhard-Gran M, Bjorvatn B. Factors associated with depressive symptoms among postnatal women in Nepal. Acta Obstet Gynecol Scand 2007; 86: 291-7 doi: 10.1080/00016340601110812.

46. Ghosh, A, \& Goswami S. Evaluation of postpartum depression in a tertiary hospital. Journal of obstetrics and gynaecology of India.2011; 61(5), 528-530.

47. Rahman A, Iqbal Z, Harrington R. Life events, social support and depression in childbirth: perspectives from a rural community in the developing world. Psychol Med 2003; 33: 1161-7 doi: $10.1017 /$ S0033291703008286.

48. Nakku JEM, Nakasi G, Mirembe F. Postpartum major depression at six weeks in primary health care: prevalence and associated factors. Afr Health Sci. 2006; 6:207-14

49. Robertson E, Celasun N, and Stewart DE. Risk factors for postpartum depression. In Stewart DE, Robertson E, Dennis C.L, Grace SL, \& Wallington T. Postpartum depression: Literature review of risk factors and interventions. University Health Network Women's Health Program 2003.

\section{Supplementary Files}

This is a list of supplementary files associated with this preprint. Click to download.

- QUESTIONNAIRE2.docx 